\title{
Characterizing Subpopulations of Neoplastic Cells in Serous Effusions
}

\author{
The Role of Immunocytochemistry
}

\author{
Conceição Queiroz, M.D., F.I.A.C., Manoel Barral-Netto, M.D., and \\ Carlos Eduardo Bacchi, M.D.
}

\begin{abstract}
OBJECTIVE: To analyze the role of immunochemistry in serous effusions.

STUDY DESIGN: We analyzed cell blocks of 18 pleural
\end{abstract} and 18 peritoneal effusions diagnosed as malignant (18), benign (14) and suspicious (4). They were immunostained by the avidin-biotin complex method with a panel of four monoclonal antibodies-CEA, Ber-EP4, LeuM1 (CD15) and $p 53$-and, for lectins (Ulex europaeus) UEA-l, ConA and ConBr. RESULTS: Seventeen of the

18 cases of adenocarcinoma were positive for CEA (95\%), 12 (66.6\%) for Ber-EP4, 11 (61\%) for CD15 and $11(61 \%)$ for $p 53$. Twelve of the $18(66.6 \%)$ were positive for UEA-1, CEA, Ber-EP4 and CD15. UEA-1 did not react with mesothelial cells. $p 53$ Gave a positive reaction in only one case, reactive mesothelial cells. Con $A$ and $\mathrm{ConBr}$ reacted indiscriminately with benign and malignant cells; thus, it was not useful in distinguishing between these cells.

CONCLUSION: In this context no antibody used alone is reliable for corroborating a diagnosis, but the selective use of a small panel of three markers (CEA, Ber-EP4 and LeuM1) can be very useful in solving diagnostic difficulties in the cytodiagnosis of serous effusions. (Acta Cytol 2001;45:18-22)

$$
\begin{aligned}
& \text { Immunocytochemistry with a small } \\
& \text { panel of monoclonal antibodies, such } \\
& \text { as CEA, Ber-EP4 and LeuM1, can } \\
& \text { give significant help in the } \\
& \text { interpretation of serous effusions in } \\
& \text { day-to-day work.... }
\end{aligned}
$$

Keywords: cells, neoplasms, immunocytochemistry, serous effusions.

A major difficulty in the cytologic examination of serous effusions, and a challenge to the diagnostic skills of the cytopathologist, is distinguishing between reactive (hypertrophic and hyperplastic) mesothelial cells and adenocarcinoma cells. ${ }^{4,41}$

In most cases the diagnosis is based on routine cytologic techniques, ${ }^{16}$ the sensitivity of which varies between $50 \%$ and $78 \% .{ }^{26,44,52}$ However, in about $15 \%$ of cases more sophisticated techniques, especially immunocytochemistry, may be necessary to improve diagnostic preci-

From the Departments of Gynecology, Obstetrics and Human Reproduction and of Anatomic Pathology and Immunology, Federal University of Bahia, Bahia, and Department of Pathology, Universidade Estadual Paulista, São Paulo, Brazil.

Dr. Queiroz is Assistant Professor, Department of Gynecology, Obstetrics and Human Reproduction, Federal University of Bahia.

Dr. Barral-Netto is Titular Professor, Department of Anatomic Pathology and Immunology, Federal University of Bahia.

Dr. Bacchi is Associate Professor, Department of Pathology, Universidade Estadual Paulista.

Address reprint requests to: Conceição Queiroz, M.D., F.I.A.C., Rua Mal, Floriano 106/1102 Canela, 40110010 Salvador, Bahia, Brazil. Financial Disclosure: The authors have no connection to any companies or products mentioned in this article. Received for publication January 20, 2000. Accepted for publication May 12, 2000. 
sion, $6,10,12,14,15,19,20,22,23,27,38,40,44,50$ and for this purpose various antibody panels have been proposed. ${ }^{11,13,28,34,49,51}$

In our study we made up a panel with some markers the sensitivity and specificity of which had already been tested, including antibodies against antigens CEA, Ber-EP4, LeuM1 and p53 and lectins Ulex europaeus (UEA-1) and Concanavalin A (ConA). CEA has been extensively evaluated for its usefulness in distinguishing mesothelial cells from adenocarcinoma cells. ${ }^{13,38,40}$

Ber-EP4 is a monoclonal antibody that identifies 34- and 39-kd cell surface glycoproteins present in epithelial cells but not in mesothelial cells. ${ }^{33}$ Leu M1 (CD15) reactivity has been identified in a variety of carcinomas, particularly lung cancer, while reactive mesothelial cells are negative. ${ }^{13,50}$ Mutated forms of p53 accumulate in the nucleus, where they are more readily detectable by immunohistochemistry. ${ }^{7}$ It may be useful in distinguishing benign from malignant cells in pleural effusion. ${ }^{52}$ UEA-1 may help in distinguishing reactive mesothelial cells from adenocarcinoma cells in effusions. ${ }^{45,48}$ ConA is a protein isolated from the jack bean. The distribution of this lectin's binding sites on unfixed cells in effusions can help to distinguish cancer cells from mesothelial cells. ${ }^{36}$ Canavalia brasiliensis (ConBr) had not been used before for this purpose.

\section{Materials and Methods}

Thirty-six specimens, 18 pleural and 18 ascitic fluids, were selected. The available material consisted of smears stained by the Papanicolaou method and cell blocks stained with hematoxylin and eosin, together with the clinical records, histopathology reports (if any) and follow-up information.

On cytology we identified 18 adenocarcinomas, 14 benign cases and 4 cases suspicious for adenocarcinoma. The 36 specimens were tested against the panel of monoclonal antibodies and lectins listed above. We used the avidin-biotin complex (ABC) immunocytochemical method.

Of the 18 cases positive for adenocarcinoma, 15 were from women and 3 from men; their average age was 63.6 years. Ten metastatic adenocarcinomas of known primary origin were diagnosed by examination of pleural fluid: 5 pulmonary, 3 mammary, 1 ovarian and 1 of unknown origin. The other eight neoplasms, all adenocarcinomas of known primary origin, were identified in peritoneal fluid: four ovarian, one mammary and one colonic. Of the four specimens reported as suspicious, 3 were from patients who had a history of neoplasms: adenocarcinomas of lung, stomach and skin.

Cell block sections were placed on slides covered with saline, deparaffinized in xylene and dehydrat-

\section{UEA-1 can be useful in distingushing adenocarcinoma cells from reactive mesothelial cells.}

ed in ethanol. Before incubation with the primary antibodies and lectins, the sections underwent treatment with trypsin or microwaves in citratebuffered solution, $0.01 \mathrm{M}, \mathrm{pH} 6.0$, with the aim of antigen recovery. After overnight incubation with primary antibodies/lectin (anti-CEA rabbit antiserum [Ortho Diagnostic Systems, Carpinteria, California, U.S.A.], 1:800; epithelial antigen, mouse Ber-EP4, M08D4 [Dako, Glostrup, Denmark], 1:100; mouse granulocyte-associated antigen MO733 [Dako], 1:100; p53 protein M701 [Dako], 1:50; UEA1 agglutinin I, L1060 [Vector Laboratories, Burlingame, California, U.S.A.], 1:800; Canavalia ensiformis (CE), 1:100; ConBr, 1:100), the sections reacted with secondary antibodies for 60 minutes. The antigen-antibody complex and lectins were localized using the ABC-diaminobenzidineperoxidase method. The smears were cross-stained with hematoxylin or methyl-green and subsequently analyzed by two observers (C.Q. and C.E.B.) according to the reactivity model for each marker and were classified as positive or negative. The statistical calculation of sensitivity and specificity used the cytologic diagnosis from cell blocks as the standard.

\section{Results}

The CEA reaction was positive in 17 of the 18 adenocarcinomas and in 1 cytologically suspicious specimen, with the positivity cytoplasmic. CEA was not detected in mesothelial cells, but there was a positive reaction in the accompanying polymorphonuclear leukocytes due to the nonspecific reaction of the cytoplasmic granules.

The Ber-EP4 reaction was positive in 12 cases of adenocarcinoma, with the positivity (usually intense) predominantly in the cell membranes. Mesothelial cells gave a negative reaction.

The CD15 (LeuM1) reaction was positive in 11 cases of adenocarcinoma and was not positive in any benign case. Immunostaining for CD15 was 
predominantly in the cell membranes of carcinoma cells.

p53 Was positive in 15 of the 36 cases examined. It was positive in 11 cases of adenocarcinoma, 1 negative specimen and 3 cytologically suspicious specimens. The immunostaining was nuclear. Mesothelial cells gave a negative reaction.

The UEA-1 reaction was positive in 12 of the 18 cases of adenocarcinoma. The carcinoma cells that reacted positively showed a cytoplasmic staining reaction. The staining for UEA-1 was negative in all benign cases. The ConA reaction (cytoplasmic) was positive in all cases, in both benign and malignant cells, with $100 \%$ sensitivity and $0 \%$ specificity. The ConBr reaction (cytoplasmic) was positive in all cases, in both benign and malignant cells, with $100 \%$ sensitivity and $0 \%$ specificity

\section{Discussion}

Distinguishing reactive mesothelial cells from adenocarcinoma cells in serous fluid is a common problem. Despite the absence of a specific, reliable marker for mesothelial cells, the detection of glycoprotein epitopes Ber-Ep4 and LeuM1 has been shown to offer valuable support to conventional diagnostic techniques. ${ }^{11,13,28,33,51}$

Detection of CEA in cells seems to definitively exclude a mesothelial origin. 1,8,10,25,26,34,37,43,46,47,51 In our specimens CEA was positive in 1 of 4 cases reported as suspicious and negative in 1 case of ovarian cystadenocarcinoma (the only case among the 18 cases of adenocarcinoma that was negative for this marker), which agrees with previous studies.1,20 This case was also negative for Ber-EP4, CD15, p53 protein and UEA-1. In 10 cases of serous adenocarcinoma of the ovaries, Khoury et al, after finding that only three reacted with LeuM1 and B72.3 and $40 \%$ stained for CEA, concluded that immunonegative results must be interpreted with much caution, especially in serous tumors. ${ }^{31}$

Sheibani et $\mathrm{al}^{47}$ analyzed $>500$ diffuse malignant mesotheliomas of epithelial type that were well characterized clinically and morphologically with various monoclonal and polyclonal antibodies reactive against oncofetal antigens, intermediate filaments, lectins and mucoid material. They found that LeuM1, CEA and Ber-EP4 were the most useful reactors for distinguishing between mesotheliomas and adenocarcinomas. ${ }^{35}$ Hartman concluded that expression of CEA and LeuM1 by tumor cells virtually excludes mesothelioma. ${ }^{28}$ In the cases studied by Gaffey, where 10 of 49 pleural and peri- toneal mesotheliomas were positive for Ber-EP4, it was not clear if they were peritoneal or pleural tumors. ${ }^{17}$

Of our four cytologically suspicious cases stained for $\mathrm{p} 53$, three were positive. Follow-up of these patients showed that three had histologic or clinical evidence of cancer. These results suggest that the reaction for $\mathrm{p} 53$ is a good pointer to malignancy, indicating, perhaps, that in these cases the reactive cells have undergone malignant change but that they have not yet acquired the phenotypic changes detectable by conventional cytologic techniques. The reaction for p53 was positive in one of 14 cases reported cytologically as benign, in a 6-year-old girl with a diagnosis of acute hepatitis. Reactivity with p53 in benign cells has been reported. ${ }^{11}$

According to the literature, ConA is not a useful marker for distinguishing between mesothelial and adenocarcinoma cells. 5,9,45,49 ConBr showed identical immunocytochemical behavior. Despite the fact that these lectins belong to the same genus and have a high level of homology $(80 \% / 90 \%)$ in relation to their primary structures, they have shown differences in biologic behavior. ${ }^{3,21}$ These differences can be explained by the different sites of affinity between the lectins and receptors that trigger biologic effects, but they are not enough to show a distinct immunocytochemical reaction. ${ }^{18,39}$

In considering a combination of antibodies containing at least one positive marker sensitive for adenocarcinoma, both CEA/CD15 and BerEP4/CD15 had 100\% sensitivity. A positive reaction for CEA and/or CD15 has been shown to be the best immunocytochemical combination for adenocarcinoma, and a negative reaction for both would be the best indicator of mesothelioma. ${ }^{24}$

A panel made up of CEA, Ber-EP4 and LeuM1 is highly sensitive and extremely specific in detecting adenocarcinoma cells in cell blocks from serous effusions, resulting in a more accurate diagnosis. The failure of cytologically positive cases to react with one or more of these markers (one case for CEA, six for Ber-EP4 and seven for LeuM1) was probably due more to the absence of expression of the detectable molecules by these antibodies rather than to genetic abnormalities occurring in clones of metastatic cells. ${ }^{13}$ Perhaps some sort of masking of the epitopes during fixation and processing could have reduced the immunoreactivity. We cannot exclude, however, the true absence of these antigens in adenocarcimona cells that did not express these markers. 
Immunoreactivity for p53 can aid in detecting neoplastic cells and is a strong indicator of malignancy even in cytologically benign cases. $7,29,30,32$

UEA-1 can be useful in distinguishing adenocarcinoma cells ${ }^{2}$ from reactive mesothelial cells.

The lectins ConA and ConBr did not show any specificity and were not capable of distinguishing neoplastic populations from reactive mesothelial cells. However, the use of $\mathrm{ConBr}$ in immunocytochemistry opens up an avenue of research, in the sense of trying to find other Brazilian lectins that could be used in characterizing tumors.

\section{Conclusion}

Distinguishing reactive mesothelial cells from adenocarcinoma cells is a common problem in the cytodiagnosis of serous fluids. Despite the current absence of a specific and reliable marker for mesothelial cells, the detection of glycoprotein epitopes, including CEA and those recognized by BerEP4 and LeuM1 antibodies, has been shown to offer valuable support to conventional diagnostic techniques.

Immunocytochemistry with a small panel of monoclonal antibodies, such as CEA, Ber-EP4 and LeuM1, can give significant help in the interpretation of serous effusions in day-to-day work, increasing diagnostic accuracy and being easy and economical to perform.

Our results indicate that UEA-1 can be useful in distinguishing adenocarcinoma cells from reactive mesothelial cells. The lectins ConA and ConBr did not show any specificity and were not capable of distinguishing neoplastic populations from reactive mesothelial cells.

\section{Acknowledgements}

The authors thank Dr. Bernard Naylor for his valuable help with the manuscript.

\section{References}

1. Abramenko IV, Gluzman DF, Sklyarenko LM, Pisnyachevskaya G, PinchoukVG: Immunocytochemical staining of cells in 153 pleural effusions with a panel of monoclonal antibodies and lectins. Anticancer Res 1991;11:629-634

2. Aoki D, Nozawa S, lizuka R, Kawakami H, Hirano H: Differences in lectin patterns of normal endometrium and endometrial adenocarcinoma, with special reference to staining with Ulex europaeus agglutinin 1 and Peanut agglutinin. Gynecol Oncol 1990;37:338-345

3. Barral-Netto M, Santos SB, Barral A, Moreira L, Santos CF, Moreira RA, Oliveira JTA: Human lymphocyte stimulation by legume lectins from the Diocleae tribe. Immunol Invest 1992;21:297-303
4. Bedrossian CWM: Workshop on Cytopathology of serous effusion: Differential diagnosis by multimodal approach. Annual Scientific Meeting of the American Society of Cytopathology, New York, November 7-12, 1995

5. Ben-Cheng F, Zhen-de X, Jing-Hui H: Location of lectin Ulex receptors in histological diagnosis of nasopharyngeal precancerous lesion. Chin Med J 1992;105:494-499

6. Carrillo R, Sneige N, El-Naggar AK: Interphase nucleolar organizer regions in the evaluation of serosal cavity effusions. Acta Cytol 1994;38:367-372

7. Chang F, Syrjanen S, Kurvinen K, Syrjanen K: The p53 suppressor gene as a common cellular target in human carcinogenesis. Am J Gastroenterol 1993;88:174-181

8. Cibas ES, Corson JM, Pinkus GS: The distinction of adenocarcinoma from malignant mesothelioma in cell blocks of effusions. Hum Pathol 1987;18:67-74

9. Drachenberg CB, Papadimitriou JC: Aberrant pattern of lectin binding in low and high grade prostatic intraepithelial neoplasia. Cancer 1995;75:2539-2544

10. Duggan MA, Marsters CB, Alexander F: Immunohistochemical differentiation of malignant mesothelioma, mesothelial hyperplasia and metastatic adenocarcinoma in serous effusions utilizing staining for carcinoembrionic antigen, keratins and vimentin. Acta Cytol 1987;31:807-814

11. El-Habashi A, El-Marsi B, Fueman S, El-Didi M, Marrogi AJ: Tumor oncogenic expression in malignant effusions as a possible method to enhance cytologic diagnostic sensitivity. Am J Clin Pathol 1995;103:206-214

12. Epenetos DA, Canti G, Taylor-Papadimitriou J, Curling M, Bodmer WF: Antibodies for diagnosis of malignancy in serous effusions. Lancet 1982;2:1004-1006

13. Esteban JM, Yokota S, Nusain S, Battifora H: Immunocytochemical profile of benign and carcinomatous effusions: A practical approach to difficult diagnosis. Am J Clin Pathol 1990;94:698-705

14. Finn C, Ward K, Luesley DM, Dunn JÁ, Redman CWE: Qualitative and quantitative analysis of peritoneal fluids from women with gynecologic diseases: Comparison of cytology and flow cytometry for the detection of malignancy in lavage and ascitic fluid. Analyt Quant Cytol Histol 1991;13:182-186

15. Fisher DF, Wongbunnate S, Johnston DA, Katz RL: DNA content by image analysis: An accurate discriminator of malignancy in pericardial effusions. Analyt Quant Cytol Histol 1994;16:167-173

16. Flynn MK, Johnston WW, Bigner S: Carcinoma of ovarian and other origins in effusions. Acta Cytol 1993;37:439-447

17. Gaffey MJ, Mills SE, Swanson PE, Zarbo RJ, Shah A, Wick MR: Immunoreactivity for Ber-Ep4 in adenocarcinomas, adenomatoid tumors and malignant mesotheliomas. Am J Surg Pathol 1992;16:593-599

18. Gallagher JT: Carbohydrate-binding properties of lectins: A possible approach to lectin nomenclature and classification. Biosci Rep 1984;4:621-632

19. Gavin F, Gray C, Sutton J, Clayden AD, Banks RI, Bird CC: Morphometric differences between cytologically benign and malignant serous effusions. Acta Cytol 1988;32:175-182

20. Goldblum J, Hart WN: Localized and diffuse mesotheliomas 
of the genital tract and peritoneum in women: A clinicopathologic study of nineteen true mesothelial neoplasms, other than adenomatoid tumors, multicystic mesotheliomas and localized fibrous tumors. Am J Surg Pathol 1995;19: 1124-1137

21. Gomes JC, Ferreira RR, Cavada BS, Moreira RA, Oliveira JTA: Histamine release induced by glucose (mannose)-specific lectins isolated from brazilian beans: Comparison with Concanavalin A. Agents Actions 1994;41:132-135

22. Gondos B, Lai CE, King EB: Distinction between atypical mesothelial cells and malignant cells by scanning electron microcopy. Acta Cytol 1979;23:321-326

23. Granados R, Cibas E, Fletcher J: Cytogenetic analysis of effusions from malignant mesothelioma: A diagnostic adjunct to cytology. Acta Cytol 1994;38:711-715

24. Grove A, Paulsen SM: The value of immunohistochemistry of pleural biopsy specimens in the differential diagnosis between malignant mesothelioma and metastatic carcinoma. Pathol Res Pract 1994;190:1044-1055

25. Guzman J, Bross KJ, Costabel U: Immunocytology in malignant pleural mesothelioma. Chest 1989;95:590-595

26. Guzman J, Costabel U, Bross KJ, Wiehle U, Schaefer HE: The value of the immunoperoxidase slide assay in the diagnosis of malignant pleural effusions in breast cancer. Acta Cytol 1988;32:188-192

27. Hafiz MA, Becker RL, Mikel V, Bahr G: Cytophotometric determination of DNA in mesothelioma and reactive mesothelial cells. Analyt Quant Cytol Histol 1988;10:120-126

28. Hartmann CA, Schütze H: Mesothelioma-like tumors of the pleura: A review of 72 autopsy cases. J Cancer Res Clin Oncol 1994;120:331-347

29. Kamel D, Pääkö P, Pöllänen R, Vähäkangas $K$, Lehto VP, Soini Y: Human papillomavirus DNA and abnormal p53 expression in carcinoma of the urinary bladder. APMIS 1995; 103:331-338

30. Karamis AM, Worthy E, Gorgoutis VG, Quezada M, Anastastades OT: p53 Gene alterations in special types of breast carcinoma: A molecular and immunohistochemical study in archival material. J Pathol 1995;176:361-372

31. Khoury N, Raju U, Zarbo RJ, Greenwald KA: A comparative immunohistochemical study of peritoneal and ovarian serous tumors and mesotheliomas. Human Pathol 1990;21:811-819

32. Kruprijanczyk J, Bell DA, Dimeo D, Beachamp R, Thor AO, Yandell OW: p53 Gene analysis of ovarian borderline tumors and stage 1 carcinomas. Hum Pathol 1995;26:387-392

33. Latza U, Niedobitek G, Schwarting R, Nikarda H, Stein H: Ber Ep4: New monoclonal antibody which distinguishes epithelial and mesothelial cells. J Clin Pathol 1990;43:213-219

34. Lee JS, Nam JH, Lee MC, Park CS, Juhng SW: Immunohistochemical panel for distinguishing between carcinoma and reactive mesothelial cells in serous effusions. Acta Cytol 1996;40:631-636

35. Lopez-Alvarez MD, Ariza A, Mate JL, Ruiz J, Castella I, Rosell R, Navas JJ: Mesothelioma versus adenocarcinoma: An immunohistochemical study including B72.3 and Ber-Ep4 monoclonal antibodies (abstr). Pathologia 1992;25:242
36. Lubinski J: Distribution pattern of Concanavalin A on carcinoma cells, histiocytes and mesothelial cells from effusion. Acta Cytol 1987;31:99-103

37. Marshall RJ, Herbert A, Braye SG, Jones DB: Use of antibodies to carcinoembryonic antigen and human milk fat globule to distinguish carcinoma, mesothelioma and reactive mesothelium. J Clin Pathol 1984,37:1215-1221

38. Mezger J, Stotzer O, Schilli G, Bauer S, Wilmanns W: Identification of carcinoma cells in ascitic and pleural fluid. Acta Cytol 1992;36:75-84

39. Moreira RA, Ainouz IL, Oliveira JTA, Cavada B: Plant lectins, chemical and biological aspects. Mem Inst Oswaldo Cruz (suppl 2) 1981;86:211-218

40. Moreira RA, Cavada BSC: Lectin from Canavalia brasiliensis (Mart): Isolation, characterization and behavior during germination. Biol Platarium 1984;26:113-120

41. Naylor B: Pleural, peritoneal and percardial fluids. In Comprehensive Cytopathology. Edited by M Bibbo. Philadelphia, WB Saunders, 1991

42. Permanetter $W$, Wiesinger H: Immunohistochemical study of lysozyme, alpha 1-chymotrypsin, tissue polypeptide antigen, keratin and carcinoembryonic antigen in effusion sediments. Acta Cytol 1987;31:104-112

43. Pinto MM, Bernstein IH, Brogan DA, Criscuolo EM: Carcinoembryonic antigen in effusions: A diagnostic adjunct to cytology. Acta Cytol 1987;31:113-118

44. Recker F, Otto T, Rübben H: Lectins in diagnosis of bladder carcinoma. Urol Int 1992;48:149-153

45. Rosen-Levin E, Patil JR, Watson CW, Jaguider J: Distinguishing benign from malignant pleural effusions by lectin immunocytochemistry. Acta Cytol 1989;33:499-504

46. Schimitt FC, Maeda AS, Bacchi CE: EMA and CEA in the cytology of serous effusions (in Portugese). Rev Bras Cancerol 1990;36:13-16

47. Sheibani K, Shinn SS, Kezirian J, Wiss LM: Ber-EP4 antibody as a discriminant in the differential diagnosis of malignant mesothelioma versus adenocarcinoma. Am J Surg Pathol 1991;15:779-784

48. Shield PW: Lectin binding properties of cells from serous effusions and peritoneal washing specimens. J Clin Pathol 1989;42:1178-1183

49. Stonesifer KJ, Xiang J, Wilkinson EJ, Benson NA, Braylon RC: Flow cytometric analysis and cytopathology of body cavity fluids. Acta Cytol 1987;31:125-130

50. Tickman RJ, Cohen C, Varma VA, Feket PS, De Rose P: Distinction between carcinoma cells and mesothelial cells in serous effusions: Usefulness of immunohistochemistry. Acta Cytol 1990;34:491-496

51. Tiniakos DG, Healicon RM, Hairt T, Wadehra V, Horne $\mathrm{CHW}$, Angus B: p53 Immunostaining as a marker of malignancy in cytologic preparations of body fluids. Acta Cytol 1995;39:171-176

52. Zoppi JÁ, Pellicer ME, Sundblad AS: Diagnostic value of p53 protein in the study of serous effusions. Acta Cytol 1995;39: $721-724$ 